\title{
Science and technology requirements to explore caves in our Solar System
}

\author{
A White Paper Submitted for the 2020 Planetary Science Decadal Survey
}

Timothy N. Titus ${ }^{1}$, J. Judson Wynne ${ }^{2}$, Penelope J. Boston ${ }^{3}$, Pablo de León ${ }^{4}$, Cansu Demirel-Floyd ${ }^{5}$, Heather Jones ${ }^{6}$, Francesco Sauro ${ }^{7}$, Kyle Uckert ${ }^{8}$, Ali-akbar Agha-mohammadi ${ }^{8}$, E. Calvin Alexander ${ }^{9}$, James W. Ashley ${ }^{8}$, Armando Azua-Bustos ${ }^{10,11}$, Leroy Chiao ${ }^{12}$, Glen E. Cushing ${ }^{1}$, John DeDecker $^{13}$, Alberto G. Fairén ${ }^{10,14}$, Amos Frumkin ${ }^{15}$, Jo de Waele ${ }^{7}$, Gary L. Harris ${ }^{4}$, Laura A. Kerber $^{8}$, Richard J. Léveillé ${ }^{16}$, Michael J. Malaska ${ }^{8}$, Kavya Manyapu ${ }^{4}$, Matteo Massironi ${ }^{17}$, Ana Z. Miller ${ }^{18}$, John E. Mylroie ${ }^{19}$, Bogdan P. Onac ${ }^{20}$, Scott Parazynski ${ }^{21}$, Charity Phillips-Lander ${ }^{22}$, Thomas Prettyman ${ }^{23}$, Haley Sapers ${ }^{8}$, Norbert Schorghofer ${ }^{23}$, Dirk Schulze-Makuch ${ }^{24}$, Red Whittaker $^{6}$, Kaj E. Williams ${ }^{1}$, and Uland Wong ${ }^{3}$

${ }^{1}$ U.S. Geological Survey, Astrogeology Science Center, Flagstaff, AZ(ttitus@usgs.gov); ${ }^{2}$ Department of Biological Sciences, Northern Arizona University, Flagstaff, AZ; ${ }^{3}$ NASA Ames Research Center, Moffett Field, CA; ${ }^{4}$ Human Spaceflight Laboratory, Department of Space Studies, University of North Dakota, Grand Forks, ND; ${ }^{5}$ School of Geosciences, University of Oklahoma, Norman, OK; ${ }^{6}$ Robotics Institute, Carnegie Mellon University, Pittsburgh, PA; ${ }^{7}$ Dipartimento di Scienze Biologiche, Geologiche e Ambientali, Università di Bologna, Bologna, Italy; ${ }^{8}$ NASA Jet Propulsion Laboratory, California Institute of Technology, Pasadena, CA; ${ }^{9}$ Earth \& Environmental Sciences Department University of Minnesota, Minneapolis, MN; ${ }^{10}$ Centro de Astrobiología, CSIC-INTA, Madrid, Spain; ${ }^{11}$ Instituto de Ciencias Biomédicas, Facultad de Ciencias de la Salud, Universidad Autónoma de Chile, Santiago, Chile; ${ }^{12}$ Department of Mechanical Engineering, Rice University, Houston, TX; ${ }^{13}$ Center for Mineral Resources Science, Colorado School of Mines, Golden, CO; ${ }^{14}$ Department of Astronomy, Cornell University, Ithaca, NY; ${ }^{15}$ Institute of Earth Sciences, The Hebrew University of Jerusalem, Israel; ${ }^{16}$ Department of Earth \& Planetary Sciences, McGill University, Montreal, Quebec, Canada and Geosciences Department, John Abbott College, Ste-Anne-de-Bellevue, Quebec, Canada; ${ }^{17}$ Dipartimento di Geoscienze, Università degli Studi di Padova, Padova, Italy; ${ }^{18}$ Laboratório HERCULES, University of Évora, Évora, Portugal; ${ }^{19}$ Department of Geosciences, Mississippi State University, Starkville, MS; ${ }^{20}$ School of Geosciences, University of South Florida, Tampa, FL and Emil Racoviță Institute of Speleology, Cluj-Napoca, Romania; ${ }^{21}$ Fluidity Technologies, Inc., Houston, TX; ${ }^{22}$ Southwest Research Institute, San Antonio, TX; ${ }^{23}$ Planetary Science Institute, Tucson, AZ; and, ${ }^{24}$ Astrobiology Group, Center of Astronomy and Astrophysics, Technical University of Berlin, Berlin, Germany.

Acknowledgement: A portion of the research was carried out at the Jet Propulsion Laboratory, California Institute of Technology, under a contract with the National Aeronautics and Space Administration (80NM0018D0004).

Signatories: Rodrigo Romo, Pacific International Space Center for Exploration Systems, Christopher P. McKay, NASA Ames, Akos Kereszturi, Research Centre for Astronomy and Earth Sciences, Hungary, Matthew D. Covington, University of Arkansas, Nicasio T. Jiménez-Morillo, University of Évora, Sarah Stewart Johnson, Georgetown University, Dale T. Andersen, SETI Institute, Pablo Sobron, Impossible Sensing, J.R. Skok, SETI Institute, Nancy Chanover, New Mexico State University, Cory BlackEagle, Eastern Kentucky University, Svetlana Shkolyar, USRA / NASA, George Veni, National Cave and Karst Research Institute, Christian Burlet, Geological Survey of Belgium, Evan Eshelman, Impossible Sensing, Pascal Lee, Mars Institute, SETI Institute \& NASA Ames Research Center, David T. Flannery, Queensland University of Technology, Marina Walther-Antonio Mayo Clinic, Dorothy Oehler, Planetary Science Institute, David A. Crown, Planetary Science Institute, Sophie Verheyden, Royal Belgian Institute of Natural Sciences, Hanna G. Sizemore, Planetary Science Institute, Nicole Bardabelias, University of Arizona, Faith Vilas, The Planetary Science Institute, Eldar Noe Dobrea, Planetary Science Institute, Laura Fackrell University of Georgia, Huseyin Demir, University of Georgia, Danielle Wyrick, Southwest Research Institute, Debra Buczkowski, Johns Hopkins Applied Physics Laboratory. 


\section{Introduction}

We are in the incipient phase of exploring the subterranean realm of our Solar System. Research on planetary caves requires cross-planetary-body investigations spanning multiple disciplines, including geology, climatology, astrobiology, robotics, human exploration and operations. To date, we have identified landscapes associated with caves, with varied speleogenetic processes and evolutionary mechanisms, from Mercury to Pluto (Table 1). Importantly, over 1000 potential cave openings have been identified on Mars (Cushing et al., 2007; Cushing and Okubo, 2017), and nearly 200 have been documented on the Moon (Haruyama et al. 2009; Wagner and Robinson 2014, 2015).

Table 1. Classification of Earth and potential planetary cave types (modified from Boston, 2004).

\begin{tabular}{|l|l|l|l|}
\hline \multicolumn{1}{|c|}{ Cave Type } & \multicolumn{1}{|c|}{ Dominant Processes } & \multicolumn{1}{|c|}{ Terrestrial Examples } & \multicolumn{1}{|c|}{$\begin{array}{c}\text { Potential for } \\
\text { Planetary Caves }\end{array}$} \\
\hline Solutional & Dissolved by solvent & $\begin{array}{l}\text { Karstic caves (e.g., halite, } \\
\text { gypsum, carbonate) }\end{array}$ & Mars, Titan, Ceres \\
\hline Erosional & $\begin{array}{l}\text { Mechanical abrasion (wind, } \\
\text { water, grinding, etc.) }\end{array}$ & $\begin{array}{l}\text { Sea caves, aeolian } \\
\text { rock shelters }\end{array}$ & $\begin{array}{l}\text { Mars, Venus, } \\
\text { Titan }\end{array}$ \\
\hline Tectonic & $\begin{array}{l}\text { Fractured due to internal/ } \\
\text { external movements }\end{array}$ & Tectonic caves & $\begin{array}{l}\text { Moon, Mars, Titan, } \\
\text { Europa, Enceladus, } \\
\text { Ganymede, Vesta }\end{array}$ \\
\hline Suffosional & $\begin{array}{l}\text { Constructed by fluid-borne } \\
\text { particle loss }\end{array}$ & $\begin{array}{l}\text { Mud caves, } \\
\text { thermokarst }\end{array}$ & Mars \\
\hline $\begin{array}{l}\text { Phase } \\
\text { Transition }\end{array}$ & $\begin{array}{l}\text { Melting, vaporization, } \\
\text { sublimation }\end{array}$ & $\begin{array}{l}\text { Lava tubes, glacial caves, } \\
\text { ice caves (i.e., ice in } \\
\text { bedrock) }\end{array}$ & $\begin{array}{l}\text { Moon, Mars, Venus, } \\
\text { lo, Vesta, Comets }\end{array}$ \\
\hline Constructional & $\begin{array}{l}\text { Incremental biological/ } \\
\text { accretional processes, often } \\
\text { around erosional template }\end{array}$ & $\begin{array}{l}\text { Coralline algae towers, } \\
\text { travertine spring mound } \\
\text { caves }\end{array}$ & Mars \\
\hline
\end{tabular}

Planetary caves provide access to the geologic record of the near subsurface without the need for drilling or digging, with potential for preserved volatiles including water ice (Williams et al., 2010) and organic matter (Richardson et al., 2013). Thus, caves may provide a record of volatile delivery and climate change. Moreover, these features represent a unique environment that is coupled with, but largely buffered from, surface thermal conditions. The cave climate typically reflects the average annual surface temperature at depth (Cropley, 1965; Pflitsch and Piasecki, 2003). In addition, caves provide shelter from ionizing space radiation. The stable climatic and buffered conditions of caves increase the likelihood of finding evidence of extinct or perhaps extant life (e.g., Boston et al., 2001; Northup et al., 2011; Blank et al., 2018).

Speculation on the existence of caves on other planets can be dated to the late 19th century in the lunar case (Nasmyth and Carpenter, 1874). More process-specific, geologic thinking on the production of lunar voids has increased in recent decades (e.g., Halliday, 1966; Heacock et al.,1966; Hatheway and Herring, 1970), with lava tube structures and their possible relationship to sinuous rilles as a leading speleogenetic model (e.g., Oberbeck et al., 1969). A decade later, Mars 
was added to the list of potential cave worlds when lava-tube like features were identified in Viking images (Carr et al., 1977). Horz (1985) was one of the first to suggest lava tubes could be used as shelters for human explorers. With the advent of higher spatial resolution cameras, additional volcanic and tectonic cave candidates were identified on Mars (Cushing et al., 2007; Cushing and Okubo, 2017) and subsurface void space has been confirmed for several instances on the Moon (Haruyama et al. 2009; Robinson et al., 2012; Ashley et al., 2012; Wagner and Robinson, 2014). Although the identification of possible planetary caves is currently restricted to these two bodies, the identification of geologic substrates conducive to the formation of subterranean cavities has been cataloged across the Solar System —including the terrestrial planets, asteroids (e.g. Vesta), the dwarf planets Ceres and Pluto, many of the outer Solar System icy moons (e.g., Enceladus, Europa, and Titan), and even comets (Boston et al., 2001; Massironi et al., 2015). The discussion of high porosity regoliths and the potential for astrobiologically relevant microcaves is beyond the scope of this white paper but is partially addressed in Stamenković et al. (2020).

Given these advances, a diverse and interdisciplinary community of planetary caves researchers has emerged. Their activities have been partially documented by a series of workshops and conferences over the last 13 years (Titus \& Boston, 2012; Wynne et al., 2016). These meetings brought together scientists and engineers from around the world to discuss both science needs, as well as engineering challenges for cave research on other planetary bodies.

Attendees at the last planetary caves conference (18-12 February 2020) determined that a goals and/or roadmap document, like those of the Assessment and Advisory Groups, was needed to establish a common framework for planetary cave research. This white paper is our initial conception of such an effort.

\section{Goals}

These goals (in order of boundary conditions) and objectives provide a framework for planetary caves research that emphasizes the importance of further study on speleogenetic processes, while recognizing the individuality of planetary bodies (refer to Table 2).

\section{Crosscutting themes}

Interconnecting geology, habitability, and astrobiology. A cave's geology forms the boundary conditions that determine how the cave environment (or cave climate) interacts with the surface, the atmosphere, and the deeper subsurface. Cave climate (or specific microclimates therein) can dictate whether habitable conditions existed or continue to exist. Long-term climate also may affect the preservation of biosignatures. Furthermore, the presence of life may alter the geology of both the cave interior and climate. On Earth, abiotic and biotic processes are not necessarily binary, but form a continuum between geology and biology. Thus, the interactions between geology, habitability, and astrobiology will likely determine the best approaches to investigate caves. Terrestrial analogs, in their many forms, will be the best means of investigating questions related to this triumvirate over the next decade.

Ice and other volatiles. Data on the presence, absence, and/or geochemical processes of volatile compounds (especially water ice), inform multiple cave research goals and objectives. Ice can either form or modify caves. Ice may provide a record of current climate and may contain a record of past planetary climates. Importantly, vertical to sub-vertical cave passages are efficient cold traps and may contain perennial ice, and therefore represent one of the best locations to search for evidence of past climate change and life (i.e., biosignatures or life constituents). Additionally, ice could provide an important resource for human exploration (for the Moon and Mars) and/or may 
even sustain extant life. On Earth, ice caves can occur at low latitudes (e.g., California, Oregon, New Mexico, Hawaii, and Iceland), and modeling suggests they exist at low latitudes on Mars as well (Williams et al., 2010). In the outer Solar System, other volatiles may be equally interesting, such as $\mathrm{CO}$ and $\mathrm{CO}_{2}$ super-volatiles in cometary nuclei and those involved in the methane cycle on Titan (Hayes et al., 2018).

Table 2. Science goals and objectives for planetary caves research for the next decade.

\begin{tabular}{|l|l|}
\hline \multicolumn{1}{|c|}{ Goals } & \multicolumn{1}{c|}{ Objectives } \\
\hline $\begin{array}{l}\text { 1. Determine where caves } \\
\text { occur in the Solar System }\end{array}$ & $\begin{array}{l}\text { 1a. Identify cave formation processes \& landscapes where caves occur. } \\
\text { 1b. Characterize cave attributes within those cave-bearing regions. } \\
\text { 1c. Prioritize confirmed \& potential candidates for scientific exploration. }\end{array}$ \\
\hline $\begin{array}{l}\text { 2. Define origin \& evolution } \\
\text { of planetary caves as a } \\
\text { geologic system }\end{array}$ & $\begin{array}{l}\text { 2a. Document formation processes \& evolution as part of geologic record. } \\
\text { 2b. Determine geologic structure \& composition compared to surface. } \\
\text { 2c. Establish connection of cave geologic record with deeper subsurface. }\end{array}$ \\
$\begin{array}{l}\text { 3. Characterize processes } \\
\text { \& evolution of cave } \\
\text { climates \& their } \\
\text { habitability potential }\end{array}$ & $\begin{array}{l}\text { 3a. Resolve the conditions \& processes driving current cave climates. } \\
\text { 3b. Describe the history \& processes that governed past cave climates. } \\
\text { 3c. Determine the volume, sources, sinks, \& stability of cave ice. } \\
\text { 3d. Understand the radiation environment within planetary caves. }\end{array}$ \\
$\begin{array}{l}\text { 4. Examine if planetary } \\
\text { caves hosted/still host life }\end{array}$ & $\begin{array}{l}\text { 4a. Search for evidence of extinct/extant life (i.e., biosignatures). } \\
\text { 4c. Identify possible interactions between life \& cave envrionment. }\end{array}$ \\
\hline $\begin{array}{l}\text { 5. Prepare for human } \\
\text { exploration }\end{array}$ & $\begin{array}{l}\text { 5a. Acquire data to design, plan, \& safely execute exploration \& habitation. } \\
\text { 5b. Develop capacity for in situ resource utilization. } \\
\text { 5c. Devise strategy to comply with planetary protection protocols. }\end{array}$ \\
\hline
\end{tabular}

\section{Roadmap for the scientific exploration of planetary caves}

The status of planetary cave exploration varies across the Solar System. Even though Earth represents the most advanced stage of development, many questions remain unanswered about terrestrial caves and how they might serve as planetary analogs. Beyond Earth, planetary caves exploration is most advanced for the Moon and Mars, given that confirmed and candidate cave entrances are now well known and several missions and mission concepts to examine those entrances have been proposed. A cave exploration roadmap for the next decade could be divided into three phases: identification, characterization, and exploration (Table 3). Developing capabilities is a crosscutting theme that applies to all phases and includes the continued development of models and technology, as well as continued validation of both cave science and exploration technologies.

Identification. On Earth, caves are found by a combination of geological and geomorphological map analyses and their direct reconnaissance in the field (e.g., Ground Penetrating Radar). More advanced, albeit still somewhat experimental techniques, include combining thermal and visible imaging (e.g., Rinker, 1975; Cushing \& Okubo, 2017; Wynne et al. 2015). These techniques should be fully developed and expanded upon to detect caves on other planetary bodies. Limiting the search area by first identifying cave-bearing landscapes, and then systematically searching for caves via standard context imaging that accompanies most space missions is another approach that has been successfully used (e.g., Cushing \& Okubo, 2017). However, to identify specific features, 
such as possible cave entrances, skylights, or collapse pits, high spatial resolution imaging is needed. Other remote sensing techniques, if deployed with enough spatial resolution, include radar, electrical resistivity imaging (Selim et al., 2014), and gravimetry (Chappaz et al., 2016). The use of terrestrial analog studies will be required to test these techniques for the identification of caves. Once these techniques have successfully demonstrated their use in the identification of terrestrial caves, further development will be required to expand these capabilities to the search for caves on other planetary bodies.

Table 3. Planetary caves architecture for the next 10 years.

\begin{tabular}{|c|c|c|c|c|c|c|}
\hline Phase & Stage & Platform & Technology & Capability & Current & Next Decade \\
\hline \multirow{2}{*}{ 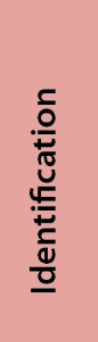 } & $\begin{array}{l}\text { Cave-bearing } \\
\text { landscapes }\end{array}$ & $\begin{array}{l}\text { Flybys \& } \\
\text { orbiters }\end{array}$ & $\begin{array}{l}\text { Low spatial } \\
\text { resolution } \\
\text { imaging }\end{array}$ & $\begin{array}{l}\text { Landscape } \\
\text { characterization }\end{array}$ & $\begin{array}{l}\text { Titan, Venus, } \\
\text { Mercury, } \\
\text { Vesta, Ceres, } \\
\text { Pluto }\end{array}$ & Europa \\
\hline & $\begin{array}{l}\text { Candidate cave } \\
\text { detection }\end{array}$ & $\begin{array}{l}\text { Orbiters \& } \\
\text { drones }\end{array}$ & $\begin{array}{l}\text { High spatial } \\
\text { resolution } \\
\text { imaging }\end{array}$ & $\begin{array}{l}\text { Candidate } \\
\text { identification }\end{array}$ & $\begin{array}{l}\text { Moon, } \\
\text { Mars }\end{array}$ & $\begin{array}{l}\text { Europa, } \\
\text { Titan, Ceres }\end{array}$ \\
\hline \multirow{2}{*}{ 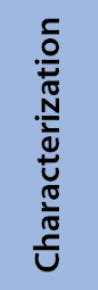 } & Cave confirmation & $\begin{array}{l}\text { Drones, } \\
\text { rovers }\end{array}$ & $\begin{array}{l}\text { Imaging \& } \\
\text { climate data } \\
\text { aquisition }\end{array}$ & $\begin{array}{l}\text { Science target(s) } \\
\text { selected }\end{array}$ & None & $\begin{array}{l}\text { Moon, Mars, } \\
\text { Titan, Ceres }\end{array}$ \\
\hline & Reconnaissance & $\begin{array}{l}\text { Drones, } \\
\text { crawlers, } \\
\text { microbots }\end{array}$ & $\begin{array}{l}\text { Imaging \& } \\
\text { mapping of } \\
\text { cave entrance }\end{array}$ & $\begin{array}{l}\text { Entrance(s) } \\
\text { examined }\end{array}$ & None & $\begin{array}{l}\text { Moon, } \\
\text { Mars }\end{array}$ \\
\hline \multirow{2}{*}{$\begin{array}{l}\stackrel{5}{\frac{0}{0}} \\
\frac{0}{\frac{0}{0}} \\
\frac{0}{0} \\
\frac{0}{x}\end{array}$} & Examination & $\begin{array}{l}\text { Drones, } \\
\text { crawlers, } \\
\text { microbots }\end{array}$ & $\begin{array}{l}\text { Active sensors } \\
\text { \& mapping }\end{array}$ & $\begin{array}{l}\text { Deep cave } \\
\text { science \& } \\
\text { exploration }\end{array}$ & -- & $\begin{array}{l}\text { Advance } \\
\text { technologies }\end{array}$ \\
\hline & Monitoring & $\begin{array}{l}\text { In situ } \\
\text { sensor } \\
\text { networks }\end{array}$ & $\begin{array}{l}\text { Climate, } \\
\text { seismic, \& } \\
\text { radiation }\end{array}$ & $\begin{array}{l}\text { Long-term cave } \\
\text { environment } \\
\text { characterization }\end{array}$ & -- & $\begin{array}{l}\text { Advance } \\
\text { technologies }\end{array}$ \\
\hline
\end{tabular}

Characterization. Confirmation that a void space in the ground is a cave entrance (rather than simply a deep pit) will be required before deploying additional exploration and science assets, and the cave must have been evaluated and determined to be a high-priority science target. Planned missions like the Mars 2020 Helicopter and Titan's Dragonfly, and proposed missions like Moon Diver, provide examples of spacecraft platforms that could be used to evaluate and/or confirm scientifically interesting cave access points. Surface rovers could also be useful for reconnaissance, given favorable cave-entrance morphology, or if equipped with ground-penetrating sensors. Further development and refinement of these types of platforms should continue. Technologies that could remotely delineate the internal structure of caves is another important area of research. For bodies with substantial atmospheres, air flow (e.g. cave breathing) may be indicative of a large subsurface void space for single entrance caves (Wigley, 1967). Meteorological stations located in or near a cave entrance could provide the much needed data to further model the extent and internal characteristics of the cave. Developing these and other methods to evaluate features 
identified as large caves would further reduce mission risk, and terrestrial analog studies will be required to fully develop these capabilities over the next decade.

Exploration. Currently, no missions are planned to enter and explore caves on other planets. Now is a good time to invest in long-lead technology development that is needed to follow up once target caves have been identified and access points sufficiently characterized. Various mission concepts have been proposed (e.g., Kerber et al., 2019; Phillips-Lander et al., 2020). Challenges include mobility, communications, navigation, and power. A range of platforms is currently under various stages of development that include (but are not limited to) robots with limbs (e.g., Parness et al., 2017), flying robot swarms (e.g., Kalita et al., 2017), a tethered rover (e.g., Nesnas et al., 2012), swarms of microbots (e.g., Kesner et al., 2007), and deployable stationary payloads (e.g., Dille et al., 2020). Each type of platform has its unique capabilities and limitations; which to select will depend on the cave to be explored. Continued development of all these types of platforms are needed for future mission flexibility, which will benefit both cave and other planetary missions.

Regardless of the robotic platform, once inside a cave, communication is no longer direct lineof-sight to either an orbiter or to Earth. Communications will require an extra step not needed for surface rovers, such as relaying between nodes, tethering, transmitting low frequency radio waves through the overburden, or returning to the cave entrance after an exploration forays (Martz et al., 2020). Bandwidth will be limited, and data downlinks will need to be compressed and prioritized. Onboard processing may be needed to interpret data for follow-up measurements. Continued development of communication hardware and software is needed over the next decade.

Due to limited communications from within the cave to the surface, navigation will need to be autonomous. Robots must autonomously detect hazards and select safe and scientifically useful trajectories. Because caves are devoid of natural lighting, active sensors will be needed. Ideally, a suite of navigation instruments would perform the dual role of both science and navigation. Continued development of this capability is needed.

Power is needed for all aspects discussed above and will be the determining factor in the length of the mission. This is expected to be the critical component for any subsurface void exploration mission; innovation may be needed to solve this problem.

\section{Conclusions and recommendations}

Planetary caves research and exploration has the potential to exponentially expand over the next decade. Before we can explore caves beyond Earth, we must find them, confirm they are highpriority scientific targets, and characterize their entrances/interiors remotely.

We suggest two complementary strategies for different parts of the Solar System: (1) develop on Earth, demonstrate on the Moon (where practical), and deploy to Mars and (2) expand high spatial resolution imaging to map the surfaces of more planetary bodies. Under the first approach, the technologies needed for Mars subsurface reconnaissance and exploration could be tested on the Moon first, in line with the LEAG Roadmap and supporting all four MEPAG Goals.

Finding caves on more Solar System bodies requires collecting data with a resolution high enough to detect caves and cave openings. Data sets that could be used to determine topography would have added benefit. For airless and transparent atmospheric planetary bodies, HiRISE/LROC-type imagers would suffice. Orbiting radar or aerial platforms may be needed for Venus and Titan. Expanding the capabilities and use of drones for high spatial resolution cave detection and entrance characterization (especially lateral entrances) is needed for future mission planning. The development of flight-qualified instruments that can resolve (and characterize) nearsurface void interiors using remote sensing are also needed. 
Continued cave climate modeling and analog studies are needed to identify the best approach(es) to characterize cave entrances and interiors remotely. This will amplify our ability to address key science questions related to habitability and astrobiology potential.

Finally, robotic development must continue along several simultaneous fronts. Technological capabilities associated with aerial drones for both entrance reconnaissance and possible interior surveys, rovers for entrance and surface reconnaissance, crawlers for entrance and interior investigations, and single axle tethered rovers for entrance and interior studies should all continue to advance in parallel. If these technologies can be sufficiently matured over the next decade, NASA will gain the flexibility to choose the appropriate exploration platform for the structure of the cave selected.

\section{References}

Ashley, J. W., M. S. Robinson, B. R. Hawke, et al., 2012, Geology of the King crater region: New insights into impact melt dynamics on the Moon, J. Geophys. Res. 117, E00H29.

Blank, J.G., Roush, T.L., Stoker, C.L., et al., 2018, Planetary Caves as Astrobiology Targets: A White Paper Submitted to the Space Studies Board of the National Academy of Sciences, January 8, 2018, 5.

Boston, P.J., 2004. Extraterrestrial caves: Encyclopedia of Caves (editors, Culver, D.C., and White, W.B.), Amsterdam, NL, Elsevier Academic Press, p. 355-358.

Boston, P., Frederick, G., Welch, S. et al., 2004, Human utilization of subsurface extraterrestrial environments: Gravitational and Space Biology Bulletin, 16(2), 121-131.

Boston, P.J., Spilde, M.N., Northup, D.E., et al., 2001, Cave biosignature suites: Microbes, minerals, and Mars: Astrobiology, 1(1), 25-55.

Carr, M.H., Greeley, R., Blasius, K.R., Guest, J.E., and Murray, J.B., 1977, Some Martian volcanic features as viewed from the Viking orbiters: J. Geophy. Res., 82(28), 3985.

Chappaz et al., 2016, Evidence of large empty lava tubes on the Moon using GRAIL gravity, Geophys. Res. Lett., 44(1), 105.

Cushing, G.E., Titus, T.N., Wynne, J.J., and Christensen, P. 2007, THEMIS observes possible cave skylights on Mars: Geophysical Research Letters, v. 34, p. L17201.

Cushing, G.E., and Okubo, C.H., 2017, Description of the Mars Global Cave Candidate Catalog (MGC3) PDS Archive.

Cropley, J.B., 1965, Influence of surface conditions on temperatures in large cave systems: National Speleological Society Bulletin v. 27, p. 1-9.

Dille et al., 2020, PHALANX: Expendable Projectile Sensor Networks for Planetary Exploration: IEEE Aerospace Conference, March 9-13, 2020.

Halliday, W.R., 1966.Terrestrial pseudo karst and the lunar topography. Bulletin of the National Speleological Society 28 (4), 167-170.

Haruyama, J., Hioki, K., Shirao, M., and eight others., 2009, Possible lunar lava tube skylight observed by SELENE cameras: Geophysical Research Letters, 36(21), L21206.

Hayes, A. G., Lorenz, R. D., Lunine, J. I., 2018, A post-Cassini view of Titan's methane-based hydrologic cycle: Nature Geoscience, Volume 11, Issue 5, p.306-313.

Hatheway, A.W., Herring, A., 1970. Bandera lava tubes of New Mexico, and lunar implications, Communications of lunar and planetary laboratory. University of Arizona 8 (152), 299-327.

Heacock, R. L., Kuiper, G. P., Shoemaker, E. M., Urey, H. C., Whitaker, E. A., 1966. Ranger VIII and IX PartII. Experimenters' Analyses and Interpretations. JPL Tech. Report 32-800.

Horz, F., 1985, Lava tubes-Potential shelters for habitats. Lunar bases and space activities of the 21 st century, Lunar and Planetary Institute, Houston, TX, A86-30113 13-14, p. 405-412.

Kalita, H., Nallapu, R. T., Warren, A., and Thangavelautham, J., 2017, GNC of the SphereX robot for extreme environment exploration on Mars, Proceedings of the 40th Annual AAS Guidance, Navigation and Control Conference, 2017, preprint arXiv:1701.07550.

Kerber L., et al., 2019, Moon diver: A Discovery mission concept for understanding secondary crust formation through the exploration of a lunar mare pit cross-section. LPSC, 50, 2132. 
Kesner, S.B., Plante, J.S., Boston, P.J., Fabian, T., and Dubowsky, S., 2007, Mobility and power feasibility of a microbot team system for extraterrestrial cave exploration. In 2007 IEEE International Conference on Robotics and Automation, IEEE, 4893-4898.

Martz, J., Al-Sabban, W. and Smith, R., 2020, Survey of unmanned subterranean exploration, navigation, and localisation. IET Cyber-systems and Robotics, 2, 1.

Massironi, M., Simioni, E., Marzari, F., and seven others, 2015, Two independent and primitive envelopes of the bilobate nucleus of comet 67P: Nature, 526(7573), 402-405.

Nasmyth, J. and Carpenter, J., 1874, The Moon: Considered as a Planet, a World, and a Satellite, London, John Murray, Albemarie Street.

Nesnas, I.A., Matthews, J.B., Abad-Manterola, P., and four others, 2012, Axel and DuAxel rovers for the sustainable exploration of extreme terrains: Joun. of Field Robotics, 29(4), 663.

Northup, D.E., Melim, L.A., Spilde, M.N., and seven others, 2011, Lava cave microbial communities within mats and secondary mineral deposits: Implications for life detection on other planets: Astrobiology, 11(7), 601-618.

Parness, A., Abcouwer, N., Fuller, C., Wiltsie, N., Nash, J., and Kennedy, B., 2017, Lemur 3: A limbed climbing robot for extreme terrain mobility in space. In 2017 IEEE International Conference on Robotics and Automation (ICRA), IEEE, 5467-5473.

Pflitsch, A., and Piasecki, J., 2003, Detection of an airflow system in Niedzwiedzia (Bear) cave, Kletno, Poland: Journal of Cave and Karst Studies., 63, 160-173.

Phillips-Lander, C.M., Wynne, J.J., Chanover, N., and 13 others, 2020, Mars Astrobiological Cave and Internal habitability Explorer (MACIE): A New Frontiers Mission Concept. 38th Mars Exploration Program Analysis Group, Jet Propulsion Laboratory, Pasadena, CA.

Oberbeck, V.R., Quaide, W.L., and Greeley, R., 1969, On the origin of lunar sinuous rilles: Mod. Geol. 1, 75.

Richardson, C. D., Hinman, N. W., and Scott, J. R., 2013, Evidence for biological activity in mineralization of secondary sulphate deposits in a basaltic environment: Implications for the search for life in the Martian subsurface, International Journal of Astrobiology, 12(4), 357.

Rinker, J.N., 1975 Airborne infrared thermal detection of caves and crevasses: Photogrammetric Engineering and Remote Sensing, v. 41, p. 1391-1400.

Robinson M. S., J. W. Ashley, A. K. Boyd, R. V. Wagner, E. J. Speyerer, B. R. Hawke, H. Hiesinger, C. H. van der Bogert (2012), Confirmation of sublunarean voids and thin layering in mare deposits, Planet. Space Sci., 69, 18-27; doi:10.1016/j.pss.2012.05.008.

Selim, E. I., Basheer, A. A., Elqady, G., and Hafez, M. A., 2014, Dimensional Electrical Resistivity Imaging, and Ground Penetrating Radar for Imaging the Ancient Monuments at the Western Shore of Old Luxor City, Egypt, Archaeological Discovery, 2(2), ID:44619.

Stamenković, V., Tarnas, J., Lynch, K. et al., 2020, Deep Trek: Science of Subsurface Habitability \& Life on Mars, Nation Academy of Sciences white paper.

Titus, T.N., and Boston, P.J., 2012, Interdisciplinary research produces results in the understanding of planetary caves, EOS, v. 93(20), 196.

Wagner, R.V., and Robinson, M.S., 2014, Distribution, formation mechanisms, and significance of lunar pits: Icarus v. 237, p. 52-60.

Wagner, R.V., and Robinson, M.S., 2015, Update: The Search for Lunar Pits: 2nd International Planetary Caves Conference (LPI Contributions, v. 1883, abstract no. 9021.

Wigley, T. M. L., 1967, Non-steady flow through a porous medium and cave breathing, J. Geophys. Res., 72(12), 3199.

Williams, K., McKay, C. P., Toon, O., and Head, J.W., 2010, Do ice caves exist on Mars? Icarus, v. 209, p 358.

Wynne, J.J., Jenness, J., Jhabvala, M.D., Titus, T.N., and Billings, D., 2015, Detecting terrestrial caves by applying topographic analysis techniques to thermal imagery, Flagstaff, AZ: 2nd International Planetary Caves Conference, abstract no. 9029.

Wynne, J.J., Titus, T.N., and Boston, P.J., 2016, Planetary Caves' Role in Astronaut Bases and the Search for Life: EOS, v. 97, doi:10.1029/2016EO047295. 